\title{
Intestinal transkingdom analysis on the impact of antibiotic perturbation in health and critical illness
}

Bastiaan W. Haak ${ }^{*}$, Ricard Argelaguet2, Cormac M. Kinsella3, Robert F.J. Kullberg1, Jacqueline M. Lankelma1, Theodorus B.M. Hakvoort5, Floor Hugenholtz1, Sarantos Kostidis4, Martin Giera4, Wouter J. de Jonge5, Marcus J. Schultz6, Tom van Gool7, Tom van der Poll1,10, Willem M. de Vos8,9, Lia van den Hoek3, W. Joost Wiersinga $1,10^{*}$

${ }_{1}$ Center for Experimental and Molecular Medicine, Amsterdam UMC, Location AMC, Amsterdam Infection \& Immunity Institute, Amsterdam, The Netherlands

2European Molecular Biology Laboratory, European Bioinformatics Institute, Hinxton, Cambridge, United Kingdom

3Laboratory of Experimental Virology, Department of Medical Microbiology, Amsterdam UMC, Location AMC, Amsterdam, the Netherlands

${ }_{4}$ Center for Proteomics and Metabolomics, Leiden University Medical Center, Leiden, The Netherlands

5Tytgat Institute for Liver and Intestinal Research, Amsterdam UMC, Location AMC, Amsterdam, The Netherlands

${ }_{6}$ Department of Intensive Care, Amsterdam UMC, Location AMC, Amsterdam, The Netherlands

7Department of Parasitology, Amsterdam UMC, Location AMC, Amsterdam, The Netherlands 8Laboratory of Microbiology, Wageningen University, Wageningen, The Netherlands

${ }_{9}$ Research Programs Unit Immunobiology, Department of Bacteriology and Immunology, Helsinki University, Helsinski, Finland

10Department of Medicine, Division of Infectious Diseases, Amsterdam UMC, Location AMC, Amsterdam, The Netherlands

Running title: Transkingdom impact of broad-spectrum antibiotics

\section{${ }^{*}$ Correspondence:}

BWH (b.w.haak@amsterdamumc.nl)

WJW (w.j.wiersinga@amsterdamumc.nl) 


\section{Abstract}

Bacterial microbiota play a critical role in mediating local and systemic immunity, and shifts in these microbial communities have been linked to impaired outcomes in critical illness. Emerging data indicate that other intestinal organisms, including bacteriophages, viruses of eukaryotes, fungi, and protozoa, are closely interlinked with the bacterial microbiota and their host, yet their collective role during antibiotic perturbation and critical illness remains to be elucidated. Here, multi-omics factor analysis (MOFA), a novel computational strategy to systematically integrate viral, fungal and bacterial sequence data, we describe the functional impact of exposure to broad-spectrum antibiotics in healthy volunteers and critically ill patients. We observe that a loss of the anaerobic intestinal environment is directly correlated with an overgrowth of aerobic pathobionts and their corresponding bacteriophages, as well as an absolute enrichment of opportunistic yeasts capable of causing invasive disease. These findings further illustrate the complexity of transkingdom interactions within the intestinal environment, and show that modulation of the bacterial component of the microbiome has implications extending beyond this kingdom alone.

\section{Introduction}

In recent years, widespread efforts have been dedicated on elucidating the immunomodulatory impact of intestinal microorganisms in health and disease (Belkaid \& Hand, 2014; Honda \& Littman, 2012). Animal studies have shown that broad-spectrum antibiotic modulation of the intestinal microbiota enhances susceptibility to enteric and systemic infections (Schuijt et al, 2015; Clarke et al, 2010; Buffie \& Pamer, 2013). In line with these preclinical findings, our group and others have observed that exposure to broad-spectrum antimicrobial therapy profoundly distorts the composition of the intestinal microbes of critically ill patients in the Intensive Care Unit (ICU) (Lankelma et al, 2017b; McDonald et al, 2016; Zaborin et al, 2016). These disruptions within the intestinal environment enable the rapid expansion of opportunistic pathobionts and nosocomial infections, including infections with vancomycin-resistant enterococci as well as invasive disease by antibiotic-resistant Enterobacteriaceae (Haak \& Wiersinga, 2017; Taur et al, 2012; Agudelo-Ochoa et al, 2020).

Traditionally, viruses were considered solely pathogens; however, growing evidence suggests a more dynamic relationship between the virome and the host, mediated through direct interactions with the bacterial microbiome(Shkoporov \& Hill, 2019; Norman et al, 2014; Pfeiffer \& Virgin, 2016; Neil \& Cadwell, 2018). Viruses influence immune development and shape 
tissue architecture (Kuss et al, 2011; De Sordi et al, 2019), and changes in the composition of viral communities have been associated with disease severity in inflammatory bowel disease (IBD), acquired immune deficiency syndrome (AIDS), and the development of Graft versus Host Disease (GvHD) (Shkoporov \& Hill, 2019; Legoff et al, 2017; Zuo et al, 2019). Similarly, intestinal fungi have recently been acknowledged as a small but potentially important part of the intestinal ecosystem and have been shown to play a potentially immunomodulatory role in the development of colorectal cancer, IBD, and irritable bowel syndrome (IBS) (Sokol et al, 2017; Botschuijver et al, 2017; Sovran et al, 2018; Richard \& Sokol, 2019). In addition, a recent study reported that a reduction of anaerobic bacteria during the course of allogeneic hematopoietic stem cell transplantation directly facilitates the intestinal overgrowth of specific Candida species, ultimately culminating in invasive fungal disease (Zhai et al, 2020).

While these findings provide clues that specific cross-kingdom interactions potentially contribute to or exacerbate disease, a large knowledge gap remains on the composition, interactions and functions of fungi and viruses following exposure to broad-spectrum antibiotics, both in healthy volunteers and in patients with critical illness. Hence, there is an increasing need for unsupervised integrative computational frameworks that can robustly and systematically identify underlying patterns of variation across these communities in health and disease (Shkoporov \& Hill, 2019; Richard \& Sokol, 2019).

\section{Results and Discussion}

To examine the extent of these transkingdom interactions during critical illness, we collected faecal samples from 33 patients (mean age 64 years; 48\% male; Table EV1) admitted to the Intensive Care Unit (ICU) of the Amsterdam University Medical Centres, location Academic Medical Centre, Amsterdam, the Netherlands. Of these patients, 24 were admitted with sepsis while nine patients had a non-infectious diagnosis (non-septic ICU). All ICU patients were treated with between one and nine different classes of antimicrobial agents (Fig. EV1). Thirteen healthy non-smoking volunteers were evaluated as controls. Six healthy subjects received oral broad-spectrum antibiotics (ciprofloxacin $500 \mathrm{mg} \mathrm{q12h}$, vancomycin $500 \mathrm{mg}$ q8h and metronidazole $500 \mathrm{mg}$ q8h) for seven days, whereas seven subjects did not receive antibiotics. Subjects were asked to collect faecal samples before antibiotic treatment and one day after completing the course of antibiotics.

We performed sequencing of the V3-V4 region of the bacterial 16S ribosomal RNA (rRNA) gene and the fungal Intergenic Transcribed Spacer (ITS)1 rRNA gene, seeking to examine 
community compositions by characterizing fungal and bacterial sequences into exact amplicon-sequencing variants (ASVs) (Callahan et al, 2016). We simultaneously performed virus discovery next-generation sequencing (VIDISCA-NGS) (van der Hoek et al, 2012) using a validated virome-enriched library preparation (Edridge et al, 2019; Kinsella et al, 2019). Finally, we measured the presence or absence of intestinal gut protozoa using targeted polymerase chain reaction (PCR).

The bacterial microbiome of ICU patients and volunteers exposed to antibiotics included in this study has been described previously by our group (Lankelma et al, 2017b; Haak et al, 2019) (Fig. 1a). Bacterial alpha diversity and richness dropped significantly in ICU patients and healthy subjects exposed to antibiotics, with the latter most significantly impacted in both metrics (Fig. 1b). In line with earlier observations (Hallen-adams \& Suhr, 2017; Suhr \& HallenAdams, 2015; Nash et al, 2017), fungal communities were dominated by Candida and Saccharomyces, while Malassezia and Aspergillus were also frequently observed. Overall, fungal diversity metrics were comparable between critically ill patients and healthy controls not exposed to antibiotics, while significant drops in diversity were observed in healthy subjects after exposure to antibiotics. Viral communities were largely dominated by environmental single stranded (ss)RNA viruses and bacteriophages of the order Caudovirales. Strikingly, around $50 \%$ of the abundance of the virome consisted of cross-assembly (crAss) phages, which have recently been connected to Bacteroides spp (Dutilh et al, 2014; Shkoporov et al, 2018). No differences in viral alpha diversity were observed, yet both septic ICU patients and antibiotic perturbed volunteers displayed higher viral richness. We observed short-term temporal stability of all three kingdoms in healthy subjects not receiving antibiotics (Shkoporov et al, 2019) (Fig. EV2). In line with recent studies (van Hattem et al, 2017, 2019), we observed that a total of $30 \%$ of healthy subjects were colonized by the anaerobic gut protozoa Blastocystis hominis or Dientamoeba fragilis, yet these protozoa were undetectable following antibiotic administration (Table EV2).

In order to further understand the patterns of covariation between these intestinal communities during health and critical illness, we employed multi-omics factor analysis (MOFA), a recently developed computational framework for data integration (Argelaguet et al, 2018, 2019a). Briefly, MOFA performs unsupervised matrix factorisation simultaneously across multiple data modalities, thereby capturing the global sources of variability via a limited number of inferred factors, effectively yielding a compressed low-dimensional representation of the data. Importantly, the model disentangles the patterns of covariation that are shared across data modalities from the variation that is exclusive to a single data modality (Argelaguet et al, 2018) (Fig. 2a). This integrative strategy, initially developed for the analysis of single-cell assays 
(Argelaguet et al, 2019b), is especially effective for the analysis of sparse readouts, including microbiome data. As input to the model, we collapsed the inferred bacterial and fungal ASVs and viral reads to their respective Family or Genus level. The number of sequences were subsequently scaled using a centralized-log ratio (Aitchison, 1982), which has shown to be effective in normalizing compositional data (Gloor et al, 2017). MOFA identified six Factors with a minimum explained variance of $5 \%$ (see Materials \& Methods). Altogether, the latent representation explained $39 \%$ of the sample heterogeneity in bacteria, $39 \%$ for fungi and $19 \%$ for viral composition (Fig. 2b,c; Fig. EV3). Notably, Factor 1 and Factor 3 (sorted by variance explained) captured coordinated variability across all three kingdoms and were capable of completely partitioning transkingdom signatures pertaining to critical illness, antibiotic perturbation and health (Fig. 2d). The four remaining Factors identified sample heterogeneity related to low abundant fungal variations (Factor 2; Fig. EV4), fluorquinolone/cephalosporin exposure (Factor 4; Fig. EV5), as well as bacterial (Factor 5) and viral (Factor 6) signatures pertaining to individual ICU patients.

Factor 1, the major source of variation, was linked to a transkingdom signature driven by antibiotic perturbation in both health and critical illness, while being consistently absent in healthy subjects without antibiotic exposure (Fig. 3a,b). Specifically, bacterial taxa positively associated with this factor were facultative aerobic bacterial pathobionts that have been previously associated with critical illness(Alverdy \& Krezalek, 2017; Wischmeyer et al, 2016; Haak et al, 2017), such as Staphylococcus, Enterococcus, Klebsiella, Escherichia/Shigella and Enterobacter. Bacterial taxa that were negatively associated with this factor consisted predominantly of genera within the obligatory anaerobic families Lachnospiraceae and Ruminococcaceae, which have been identified as markers of a healthy microbiota and are linked to colonization resistance against bacterial pathobionts(Lee et al, 2017; Taur et al, 2012). Fungal taxa positively associated with this factor were characterized by yeasts capable of causing invasive disease, such as Candida, Aspergillus, and Debaryomyces (Miceli et al, 2011; Beyda et al, 2013; Zhai et al, 2020), with a relative absence of the gut constituents Filobasidium, Malassezia and Dipodascus (Suhr \& Hallen-Adams, 2015). The specific cooccurrences of fungal and bacterial taxa observed in Factor 1 are supported by previous studies. For example, members of the Lachnospiraceae family, such as Blautia and Roseburia, display a direct inhibitory effect on the growth of several Candida spp. and Saccharomyces cerevisiae, through the production of short-chain fatty acids (SCFAs) and other metabolites (Nguyen et al, 2011; García et al, 2017; Fan et al, 2015). In addition, in vitro studies have shown that metabolites produced by Candida spp. enhance the growth of $E$. coli and $S$. aureus 167 (Huseyin et al, 2017; Kong et al, 2017), providing further indications that the intestinal transkingdom signatures identified by MOFA are biologically meaningful. 
Factor 3 captured signatures present in healthy subjects receiving broad-spectrum antibiotics, with a predominance of the closely related Streptococcaceae family (Streptococcus and Lactococcus), Lactobacillales order (Lactobacillus and Granulicatella) and Actinomyceteles order (Actinomyces and Rothia). Interestingly, all these bacteria have been shown to possess mutualistic properties with Candida in oral and vaginal environments, potentially through the modification of biofilm formation (Richard \& Sokol, 2019; Arzmi et al, 2015; Kim et al, 2017; Uppuluri et al, 2017). These observations indicate that similar fungal-bacterial interactions are potentially maintained within the gastrointestinal tract, warranting further elucidation.

Notably, the majority of viral sequences that were associated with Factors 1 and 3 consisted of bacteriophages that significantly correlated with the presence of the corresponding bacterial targets in the same factor (Fig. EV6). The expansion of aerobic bacterial species during critical illness and following antibiotics can therefore potentially facilitate the enrichment of their corresponding bacteriophages (Shkoporov \& Hill, 2019; Knowles et al, 2016). Other notable viral interactions were the increase of the mycoviruses Chrysovirus and Partitivirus-which are capable of infecting fungi (Ghabrial et al, 2015)- in healthy subjects following antibiotic exposure. These findings suggest that transkingdom interactions are occurring beyond intestinal bacteria, further underscoring the complexity of relationships within the intestinal environment.

An important indicator of the influence of the bacterial microbiota on the fungal population in the gut is the dramatic increase in the fungal burden after antibiotic treatment (Richard \& Sokol, 2019). This phenomenon can partly be explained by antibiotic-induced alterations in nutrient availability, yet a loss of the direct inhibitory effects of anaerobic bacteria towards fungal expansion has also been documented (Nguyen et al, 2011; Fan et al, 2015; García et al, 2017). Therefore, to further explore the association between functional and absolute profiles of the bacterial microbiome and fungal expansion, we performed targeted bacterial 16S rRNA and fungal 18S rRNA quantitative PCRs to calculate intestinal fungal/bacterial ratios, and simultaneously quantified the absolute abundance of the SCFAs butyrate, acetate and propionate using Nuclear Magnetic Resonance (NMR) spectroscopy. We observed a strong depletion of SCFAs in both critical illness and following antibiotic perturbation, with the latter having the most significant impact (Fig. 4a,b). Notably, both conditions were associated with increased fungal/bacterial ratios, increasing as much as $10_{3}-10_{4}$ times. This decrease of SCFAs coincided with a gradient of depletion along the axis of Factors 1 and 3 (Fig. 4c). Finally, we observed that absolute faecal SCFA concentrations were inversely correlated with absolute fungal copies, with propionate levels displaying the strongest correlation $(r=0.75 ; p$ $<0.0001$, Fig. 4d). These data suggest that fungal expansion not only occurs in the context of 
204 decreased absolute bacterial abundance, but is also dependent on altered functions of the 205 remaining bacterial communities in the intestinal environment.

206 In conclusion, our findings shed light into the dynamics and shared variations between 207 kingdoms following broad-spectrum antibiotic modulation and critical illness. The short- and 208 long-term impact of these disruptions will be an important focus of future investigations.

209 

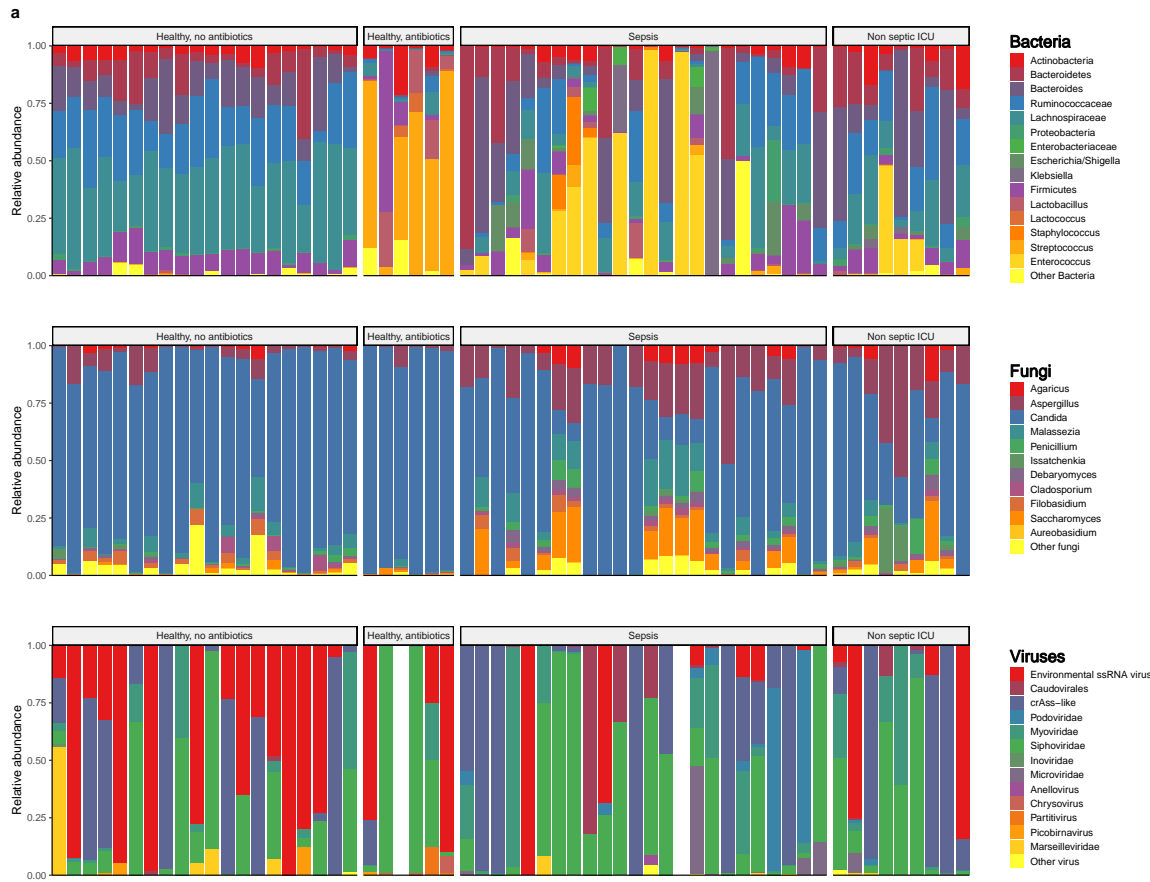
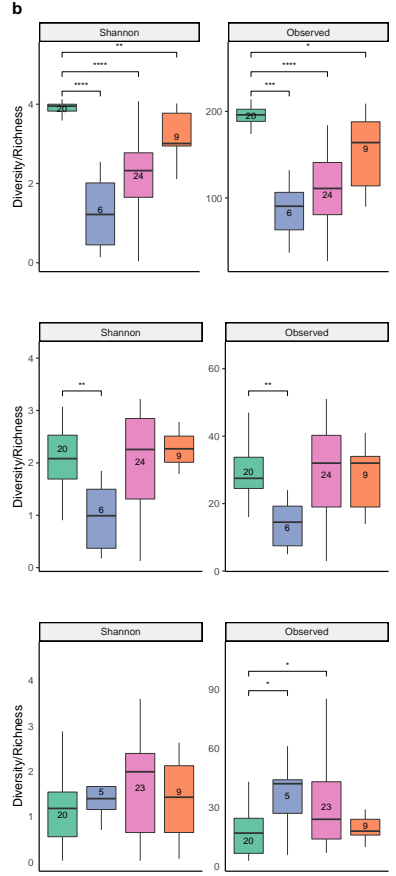

Figure 1: Overview of the composition and diversity of the bacterial, fungal and viral microbiome.

(a) Relative proportion of sequence reads at the Genus level assigned to different bacterial and fungal taxa and Order level for viral taxa. Viral metagenomics of two samples did not pass quality control due to high background levels, and were therefore excluded from further analysis. A subset of the bacterial 16S rRNA sequencing data has been previously reported.25,31

(b) Alpha diversity metrics of bacteria (top), fungi (middle) and viruses (bottom), using the Shannon Diversity Index (Shannon) and Observed Taxa richness index (Observed). In the box plots, the central rectangle spans the first quartile to the third quartile (the interquartile range or IQR), the central line inside the rectangle shows the median, and whiskers above and below the box. Given the nonparametric nature of the data, $p$ values were calculated using the Wilcoxon rank sum test. 

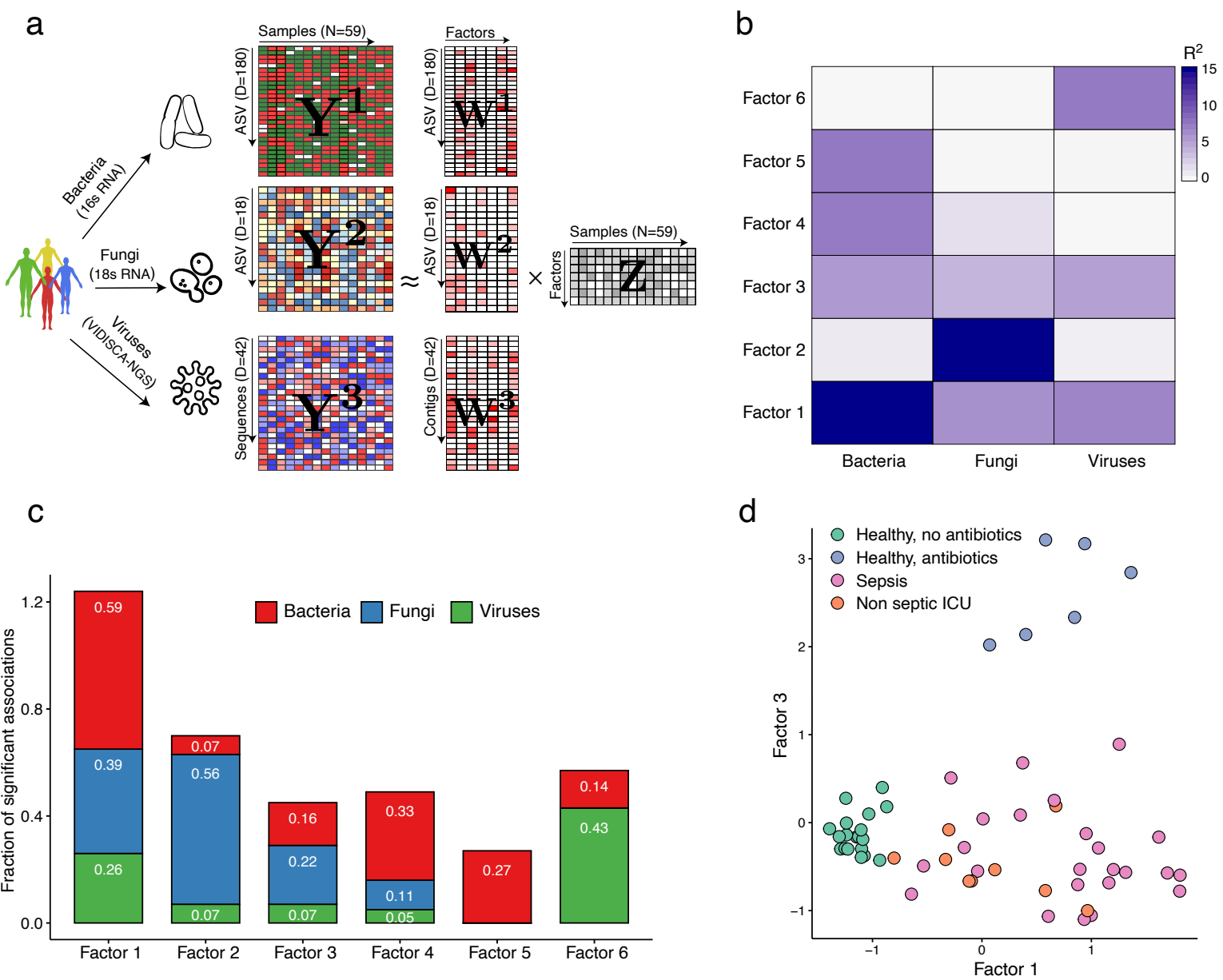

Figure 2: Multi-Omics Factor Analysis (MOFA) delineates the sources of cross-kingdom heterogeneity in the cohort.

(a) Model overview: MOFA takes as input the three microbiome quantification matrices. MOFA exploits the covariation patterns between the features within and between microbiome modalities to learn a low-dimensional representation of the data in terms of a small number of latent Factors ( $Z$ matrix) and three different weight matrices (W, one per kingdom). By maximising the variance explained under sparsity assumptions, 11,12 MOFA provides a principled way to discover the global sources of variability in the data. For each latent Factor (i.e. each source of variation), the weights provide a measure of feature importance for every feature in each Factor, hence enabling the interpretation the variation captured by every factor.

(b) Heatmap displays the percentage of variance explained (R2) by each Factor (rows) across the three microbe modalities (columns). Factors 1 and 3 capture coordinated variation across all three microbiome modalities, whereas Factor 2, 4 and 5 are mostly dominated by heterogeneity in Fungi composition.

(c) Bar plots show the fraction of significant associations between the features of each microbiome modality and each factor. P-values are obtained using a t-test based on the Pearson's product moment correlation coefficient. Statistical significance is called at 10\% FDR. This plot is useful to interpret whether the variance explained values displayed in (b) are driven by a strong change in a small number of features, or by a moderate effect across a large range of features.

(d) Scatter plot of Factor 1 (x-axis) versus Factor 3 (y-axis). Each dot represents a sample, coloured by condition. Factor 1 captures the gradient in microbiome variation associated with antibiotic treatment and critical illness (from negative to positive Factor values), whereas Factor 3 captures the variation associated with antibiotic treatment in healthy patients (positive Factor 3 values) versus critically ill patients (negative Factor 3 values). 
a

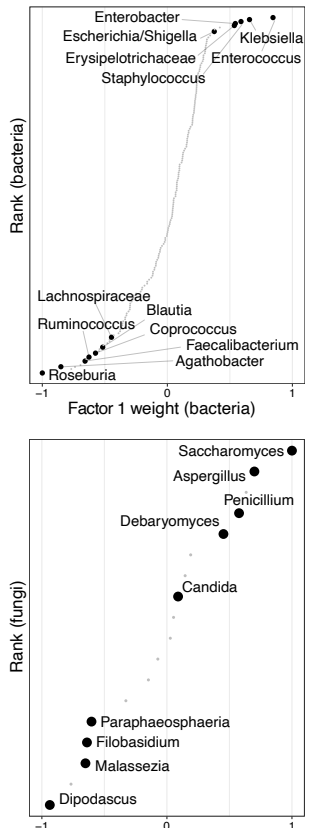

Factor 1 weight (fungi)

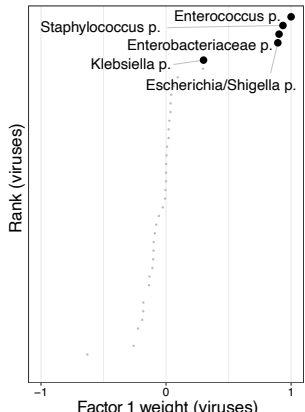

b
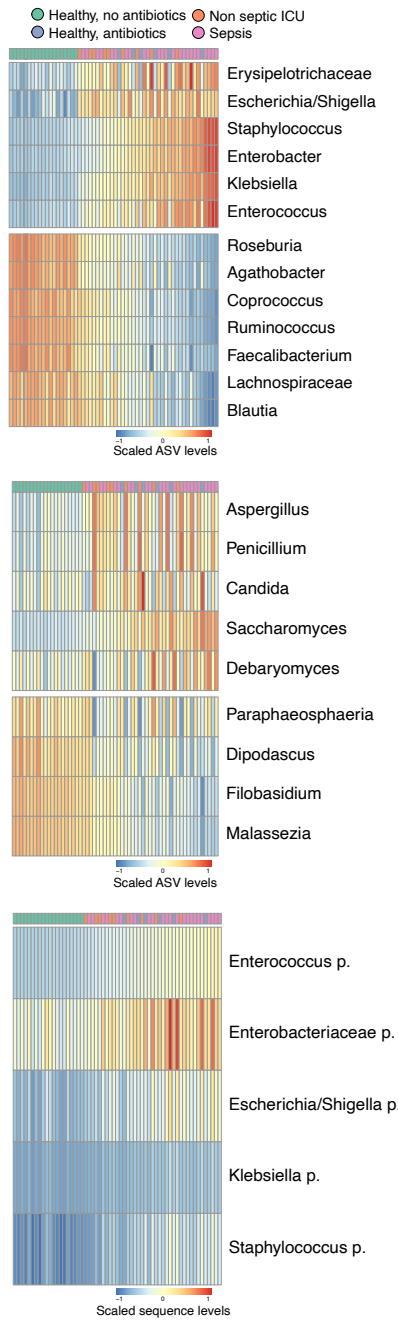

C

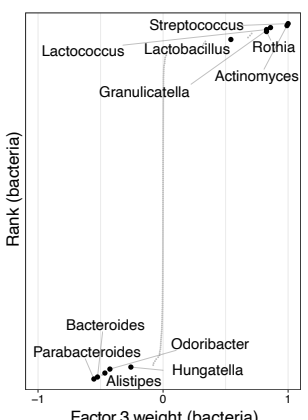

Factor 3 weight (bacteria)

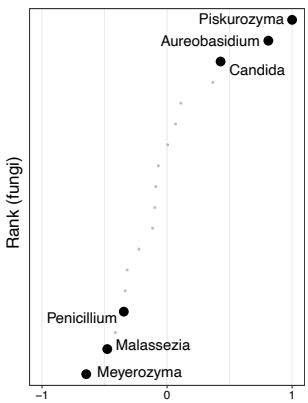

Factor 3 weight (fungi)

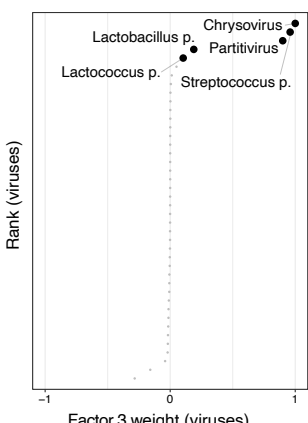

d
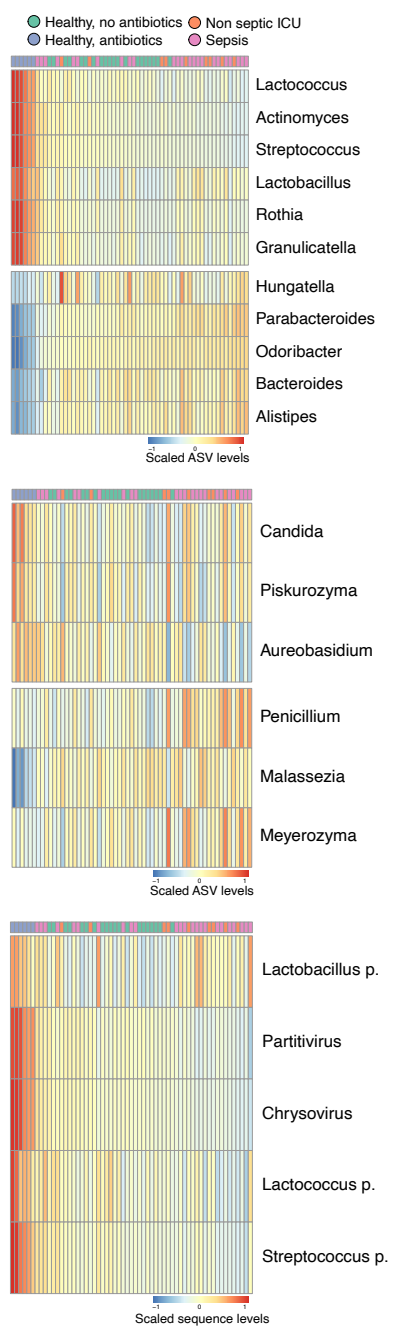

Figure 3: Characterisation of the transkingdom variation captured by Factor 1 and Factor 3.

(a) Scatter plots display the distribution of Bacterial (top), Fungi (middle) and Viruses (bottom) weights for Factor 1. A positive value indicates a positive association with Factor 1 values, whereas a negative value indicates a negative association with Factor 1 values (see Fig 2d). The larger the absolute value of the weight, the stronger the association. For ease of visualisation, weights are scaled from -1 to 1 . Representative taxa among the top weights are labeled.

(b) Heat maps display the reconstructed data (see Methods) based on the MOFA model for the taxa highlighted in (a). Samples are shown in the columns and features in the rows.

(c) Scatter plots display the distribution of Bacterial (top), Fungi (middle) and Viruses (bottom) weights for Factor 3. A positive value indicates a positive association with Factor 3 values, whereas a negative value indicates a negative association with Factor 3 values (see Fig 2d). The larger the absolute value of the weight, the stronger the association. For ease of visualisation, weights are scaled from -1 to 1 . Representative taxa among the top weights are labeled.

(d) Heat maps display the (denoised) data reconstruction (see Methods) based on the MOFA model for the taxa highlighted in (c). Samples are shown in the columns and features in the rows. 
a

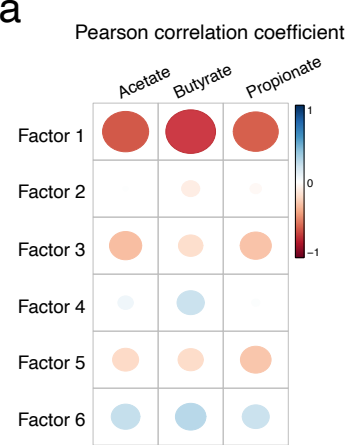

$\log 10$ FDR adjusted p-values

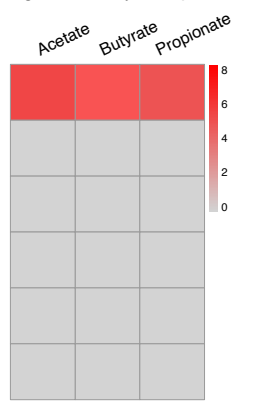

b
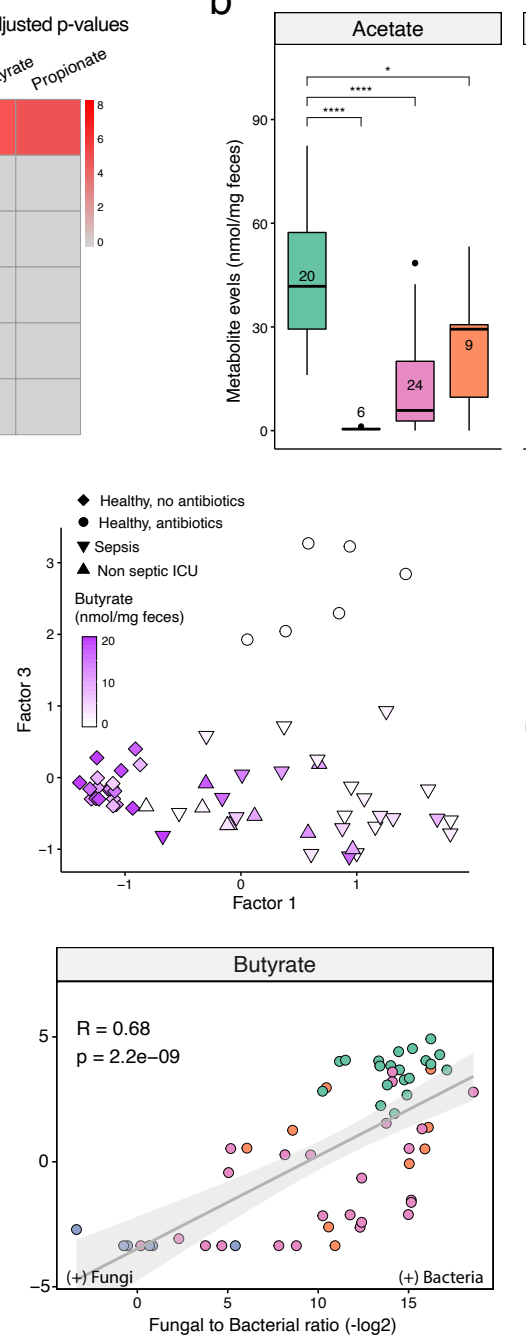

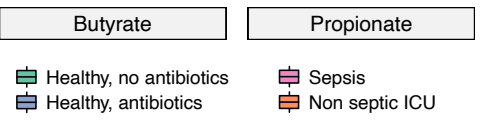

C
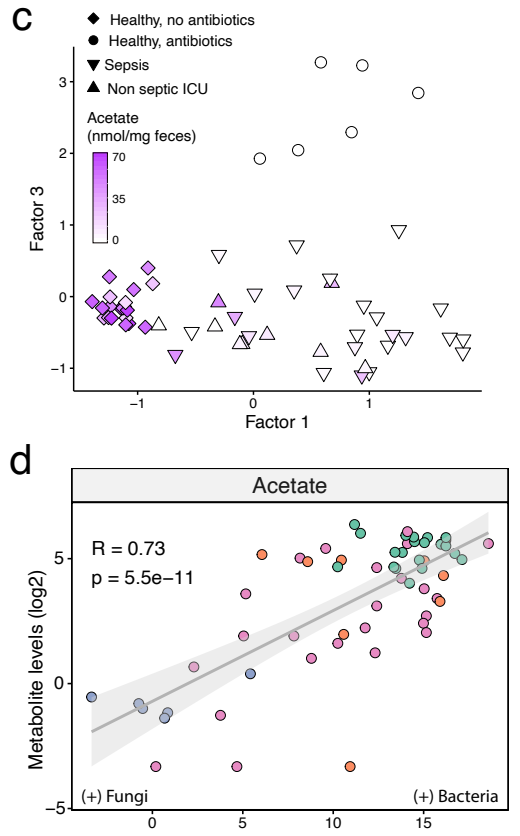

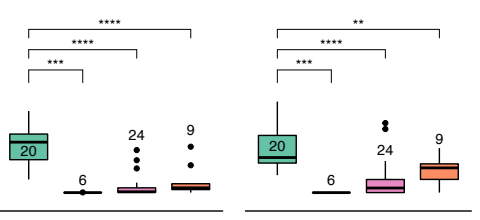

官 Healthy, antibiotics

追 Non septic ICU
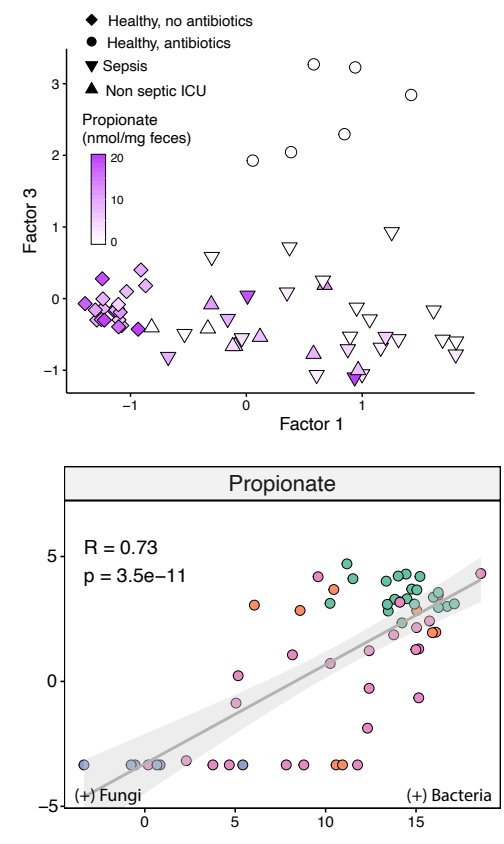

Figure 4: Correlation of total bacterial and fungal load with fecal levels of short-chain fatty acids in health and critical illness.

(a) Association analysis between Factor values and SCFA levels. Left panel displays the Pearson correlation coefficient between factor values and the levels of three types of SCFA: butyrate, acetate and propionate. Right panel displays the corresponding FDR-adjusted and log-transformed $p$-values.

(b) Box plots showing the SCFA concentrations (in mg per mg of feces, $y$-axis) per sample group ( $x$ axis). In the box plots, the central rectangle spans the first quartile to the third quartile (the interquartile range or IQR), the central line inside the rectangle shows the median, and whiskers above and below the box. Given the non-parametric nature of the data, $p$ values were calculated using the Wilcoxon rank sum test.

(c) Scatter plot of Factor 1 (x-axis) versus Factor 3 (y-axis) values. Each dot represents a sample, shaped by the sample group and coloured by SCFA concentrations (in mg per mg of feces). (d) Scatter plot of Fungal-to-Bacterial absolute levels ratio (after log10 transformation, $x$-axis) versus SCFA concentrations (after log2 transformation, $y$-axis). The line represents the linear regression fit and the shade the corresponding 95\% confidence interval. Corresponding Pearson correlation coefficients and $p$-values are also displayed in the top left corner. 


\section{Materials and Methods}

\section{Study design and participants}

Patients were recruited as part of a large prospective observational study in critically ill patients admitted to the ICU (Molecular Diagnosis and Risk Stratification of Sepsis (MARS) study; clinicaltrials.gov identifier NCT01905033) (van Vught et al, 2016; Lankelma et al, 2017b). A total of 33 randomly selected adult patients who were admitted to the ICU of the Academic Medical Centre (Amsterdam, The Netherlands) between October 2012 and November 2013 were included. Patients who were transferred from other ICUs or had an expected length of ICU stay of $<24 \mathrm{~h}$ were excluded. All patients met at least two of the following criteria: body temperature of $\leq 36$ or $\geq 38{ }^{\circ} \mathrm{C}$, tachycardia of $>90 / \mathrm{min}$, tachypnoea of $>20 / \mathrm{min}$ or partial pressure of carbon dioxide (pCO2) of $<4.3 \mathrm{kPA}$, and leukocyte count of $<4 \times 10 \mathrm{E} 9 / \mathrm{L}$ or $>12 \times$ 10E9/L. Sepsis was defined when the inclusion criteria were associated with suspected infection within 24 hours after ICU admission, with subsequent systemic therapeutic administration of antibiotics to the patient (Lankelma et al, 2017b). The control group consisted of 13 healthy, non-smoking human subjects who had not taken antibiotics during the previous year (clinicaltrials.gov identifier NCT02127749) (Haak et al, 2019; Lankelma et al, 2017a). Six healthy subjects received oral broad-spectrum antibiotics (ciprofloxacin $500 \mathrm{mg}$ q12h, vancomycin $500 \mathrm{mg}$ q8h and metronidazole $500 \mathrm{mg} \mathrm{q} 8 \mathrm{~h}$ ) for seven days. Subjects were asked to collect faecal samples before antibiotic treatment and one day after the 7-day course of antibiotics. Fresh stool samples by ICU patients were stored at $4{ }^{\circ} \mathrm{C}$ and transferred to $-80{ }^{\circ} \mathrm{C}$ within 24 hours of collection. Faecal samples by healthy subjects were collected in plastic containers, stored at $-20{ }^{\circ} \mathrm{C}$ at home and were transported to the study centre for storage at $-80^{\circ} \mathrm{C}$ within 24 hours. Written informed consent was obtained from all healthy subjects and patients or their legal representative. Ethical approval for both the patient and healthy subject studies was received from the Medical Ethics Committee of the Academic Medical Centre in Amsterdam, and all research was conducted in accordance with the declaration of Helsinki.

\section{Bacterial and fungal microbiota sequencing}

Faecal DNA was extracted and purified using a combination of repeated bead-beating (method 5) (Costea et al, 2017) and the Maxwell 16 Tissue LEV Total RNA Purification Kit (Promega, Maddison, WI, USA), with STAR (Stool transport and recovery) buffer (Roche, Basel Switzerland). Negative extraction controls (DNA-free water) were processed in a similar manner. 
Twenty nanograms of DNA was used for the amplification of the bacterial 16S rRNA gene with V3-V4 341F forward and 805R reverse for 25 cycles. The PCR was performed in a total volume of $30 \mu$ containing $1 \times$ HF buffer (Thermo Fisher Scientific, Waltham, MA, USA ), $1 \mu \mathrm{l}$ dNTP Mix (10 mM; Promega, Leiden, the Netherlands), $1 \mathrm{U}$ of Phusion Green High-Fidelity DNA Polymerase (Thermo Fisher Scientific, Waltham, MA, USA), $500 \mathrm{nM}$ of the forward 8-nt sample-specific barcode primer containing the Illumina adapter, pad and link (341F (5'CCTACGGGNGGCWGCAG-3') 500 nM of reverse 8-nt sample-specific barcode primer containing the Illumina adapter, pad and link (805R (5' GACTACHVGGGTATCTAATCC -3')) $20 \mathrm{ng} / \mu \mathrm{l}$ of template DNA and nuclease free water. The amplification program was as follows: initial denaturation at $98^{\circ} \mathrm{C}$ for $30 \mathrm{~s} ; 25$ cycles of denaturation at $98^{\circ} \mathrm{C}$ for $10 \mathrm{~s}$, annealing at $55^{\circ} \mathrm{C}$ for $20 \mathrm{~s}$, elongation at $72{ }^{\circ} \mathrm{C}$ for $90 \mathrm{~s}$; and an extension at $72{ }^{\circ} \mathrm{C}$ for $10 \mathrm{~min}$ (Kozich et al, 2013). The size of the PCR products ( $540 \mathrm{bp}$ ) was confirmed by gel electrophoresis using 4 $\mu \mathrm{l}$ of the amplification reaction mixture on a $1 \%(\mathrm{w} / \mathrm{v})$ agarose gel containing ethidium bromide (AppliChem GmbH, Darmstadt (Germany).

Fungal composition was determined by ITS1 amplicon sequence analysis. PCR generated amplicon libraries were obtained from $100 \mathrm{ng}$ faecal DNA using the ITS1 primer set containing an overhang for the Illumina Nextera platform [forward] 5'TCGTCGGCAGCGTCAGATGTGTATAAGAGACAGCTTGGTCATTTAGAGGAAGTAA and [reverse] primers and Phusion High Fidelity DNA Polymerase (Thermo Fisher Scientific, Waltham, MA, USA). A duplicate reaction in $20 \mu$ was performed with following thermocycling conditions: initial denaturation at $98^{\circ} \mathrm{C}$ for $1 \mathrm{~min}$ followed by 35 cycles denaturation (20 s), annealing (20 $\mathrm{s}$ at $58^{\circ} \mathrm{C}$ ) and extension $\left(60 \mathrm{~s}\right.$ at $\left.72^{\circ} \mathrm{C}\right)$ and final extension at $72^{\circ} \mathrm{C}$ for $5 \mathrm{~min}$. The duplicates were pooled to a final volume of $40 \mu \mathrm{l}$. The PCR products were purified with AMPure XP beads (Beckman Coulter, Brea, CA, USA) and taken into $15 \mu \mathrm{l}$ DNA-free water. A second amplification step was used to introduce multiplex indices and Illumina sequencing adapters using the Kapa polymerase system. A 24-cycle amplification reaction in $40 \mu$ was performed with following conditions: initial denaturation at $95^{\circ} \mathrm{C}$ for $3 \mathrm{~min}$ followed by denaturation (20s at $98^{\circ} \mathrm{C}$ ), annealing $\left(20 \mathrm{~s}\right.$ at $60^{\circ} \mathrm{C}$ ) and extension $\left(60 \mathrm{~s}\right.$ at $\left.72{ }^{\circ} \mathrm{C}\right)$ and final extension at $72{ }^{\circ} \mathrm{C}$ for 5 min.

Bacterial and fungal PCR products were purified using AMPure XP beads (Beckman Coulter, 
equimolarly pooled. The libraries were sequenced using an Illumina MiSeq platform (GATCBiotech, Konstanz, Germany) using V3 chemistry with $2 \times 251$ cycles. Forward and reverse reads were truncated to 240 and 210 bases respectively and merged using USEARCH (Edgar, 2010). Merged reads that did not pass the Illumina chastity filter, had an expected error rate higher than 2, or were shorter than 380 bases were filtered. Amplified Sequence Variants (ASVs) were inferred for each sample individually with a minimum abundance of 4 reads (Callahan et al, 2016). Unfiltered reads were than mapped against the collective ASV set to determine the abundances. Bacterial taxonomy was assigned using the RDP classifier (Wang et al, 2007) and SILVA 16S ribosomal database V132 (Quast et al, 2013). Fungal taxonomy was assigned using the UNITE database (Nilsson et al, 2019).

\section{Viral microbiota sequencing and analysis}

The collected faecal suspension was centrifuged to pellet cells and debris, and nucleic acids in the supernatant were extracted using the Boom method (Boom et al, 1990), followed by reverse transcription with non-ribosomal random hexamers (Endoh et al, 2005) and second strand synthesis. DNA was digested with Msel (TTAA; New England Biolabs, Ipswich, MA, USA) and ligated to adapters containing a sample identifier sequence. Next, size selection with AMPure XP beads (Beckman Coulter, Brea, CA, USA) was performed to remove small DNA fragments prior to a 28-cycle PCR using adaptor-annealing primers. Small and large size selection was performed with AMPure XP beads to select DNA-strands with a length ranging between 150 and 550 nucleotides. Libraries were analysed using the Bioanalyzer (High Sensitivity Kit, Agilent Genomics, Santa Clara, CA, USA) and Qubit (dsDNA HS Assay Kit, Thermo Fisher Scientific, Waltham, MA, USA) instruments to quantify DNA length and concentration, respectively. Sample libraries were pooled at the equimolar concentration. In total, 50 pmol DNA of the pool was clonally amplified on beads using the lon Chef System (Thermo Fisher Scientific, Waltham, MA, USA) and sequencing was performed on the lon $\mathrm{PGM}^{\text {TM }}$ System (Thermo Fisher Scientific, Waltham, MA, USA) with the ION 316 Chip (400 bp read length and 2 million sequences expected per run).

VIDISCA-NGS reads were aligned using BWA-MEM ( $\mathrm{Li}, 2013)$ to a reference database consisting of the human reference genome (hg38), the SILVA SSU V132 database(Quast et al, 2013)qu, and all RefSeq viral genomes (downloaded in September 2019). Mapping outputs were further processed using the PatholD module of PathoScope 2.0 (Hong et al, 2014; Byrd et al, 2014), to reassign reads with multiple alignments to their most likely target. Viral candidates were aligned back to the reference database with BLASTn, and those aligning at $\geq 95 \%$ for 100 bp were retained as hits. To ensure that all known eukaryotic viruses were detected with this approach, all reads that remained unmapped in the BWA-MEM step were 
analysed with a separate virus discovery bioinformatic pipeline, described in detail elsewhere (Kinsella et al, 2019). Briefly, rRNA reads were identified with SortMeRNA v2.1, non-rRNA reads were made non-redundant using CD-HIT v4.7, and these were queried against a eukaryotic virus protein database using the UBLAST algorithm provided as part of the USEARCH v10 software package (Edgar, 2010). Reads with a significant alignment to a viral protein were subsequently aligned to the non-redundant nucleotides database using BLASTn. Those with a best hit to a viral sequence were regarded as confidently viral, those not aligning to any sequences were regarded as putatively viral, while those with a non-viral best hit were regarded as false positives.

\section{Targeted measurement of intestinal protozoa}

Automated nucleic acid extraction was performed on the MagNA Pure 96 instrument (Roche Applied Science, the Netherlands) according to the manufacturer's protocol. DNA was eluted in $100 \mu$ l elution buffer (Roche Applied Science). Phocine Herpes Virus (PhoHV) DNA was added to all samples as an internal control for extraction and amplification efficiency. Presence of Giardia lamblia, Cryptosporidium parvum, Entamoeba histolytica, Blastocystis hominis and Dientamoeba fragilis was assessed by real-time PCR targeting the small subunit ribosomal RNA gene (SSU-rDNA) (van Hattem et al, 2019). Positive controls consisting of a plasmid containing the target sequence were included in every run, as well as negative extraction controls and negative PCR controls. Subjects were excluded from further analyses if internal controls tested negative in one or more samples.

\section{Targeted measurement of short-chain fatty acids}

Sample preparation of faecal extracts and Nuclear Magnetic Resonance (NMR) spectroscopy for quantification of SCFAs was performed as described in Kim HK et al (Kim et al, 2018), with some modifications. Briefly, aqueous extracts of faeces were prepared by mixing $50-100 \mathrm{mg}$ of faeces and $0.3 \mathrm{~mL}$ of deionized water, followed by mechanical homogenization in a Bullet Blender 24 (Next Avance Inc, Troy, NY, USA). The faecal slurry was centrifuged twice at 18213 $\times \mathrm{g}$ for $10 \mathrm{~min}$ at $4{ }^{\circ} \mathrm{C}$ and $0.225 \mathrm{~mL}$ of the supernatant was mixed with $0.025 \mathrm{~mL} 1.5 \mathrm{M}$ potassium phosphate buffer ( $\mathrm{pH}$ 7.4) containing $2 \mathrm{mM}$ sodium azide and $4 \mathrm{mM}$ sodium trimethylsilyl-propionate-d4 (TSP-d4) in $\mathrm{D}_{2} \mathrm{O}$. For each sample, one 1D ${ }_{1} \mathrm{H}-\mathrm{NMR}$ spectrum was acquired in a 14.1 T Avance II NMR (Bruker Biospin Ltd, Karlsruhe, Germany). Quantification of SCFAs from the NMR spectra was performed in ChenomX (Chenomx NMR suite 8.4) using the known concentration of TSP-d4.

\section{Quantitative PCR for bacterial and fungal load.}


For the measurement of total bacterial content in faecal samples, we used the method as reported by Nadkami and colleagues (Nadkarni et al, 2002), with modifications. Briefly, we used a primer concentration of $500 \mathrm{nM}$ in a final volume of $10 \mu \mathrm{l}$ with the SensiFast SYBR NoROX Kit (Bioline, London, UK). The amplification conditions were as follows: initial denaturation at $95^{\circ} \mathrm{C}$ for $5 \mathrm{~s}$ followed by denaturation $\left(10 \mathrm{~s}\right.$ at $95^{\circ} \mathrm{C}$ ) - annealing $(10 \mathrm{~s}$ at 66 ${ }^{\circ} \mathrm{C}$ ) - extension (20 s at $72{ }^{\circ} \mathrm{C}$ ) for 44 repetitive cycles in a BioRad CFX96 thermocycler (Hercules, CA, USA). The primerset of FungiQuant (Liu et al, 2012) was used for fungal load determination, with modifications. The final PCR primer concentration was $500 \mathrm{nM}$ in a volume of $10 \mu \mathrm{l}$ with the SensiFast SYBR No-ROX Kit (Bioline, London, UK). The following amplification program was used: initial denaturation at $95{ }^{\circ} \mathrm{C}$ for $5 \mathrm{~s}$ min followed by denaturation $\left(10 \mathrm{~s}\right.$ at $\left.95^{\circ} \mathrm{C}\right)$ annealing $\left(10 \mathrm{~s}\right.$ at $\left.60^{\circ} \mathrm{C}\right)$ and extension $\left(20 \mathrm{~s}\right.$ at $\left.72{ }^{\circ} \mathrm{C}\right)$ in 44 repetitive cycles in a BioRad CFX96 thermocycler (Hercules, CA, USA). Following amplification, fungal and bacterial ratios were calculated using LinRegPCR (Ruijter et al, 2009).

\section{Multi-Omics Factor Analysis (MOFA)}

The input to MOFA is a list of matrices with matching samples, where each matrix represents a different data modality. Bacterial 16S rRNA ASVs, fungal ITS1 rRNA ASVs and viral sequences were defined as separate data modalities. As a filtering criterion, bacterial and fungal features were required to have a minimum of 10 ASVs observed in at least $25 \%$ of the dataset. In addition, to mitigate the sparsity of the data and to simplify the interpretation, we collapsed the inferred bacterial and fungal ASVs and viral sequences to their respective Family or Genus level. The number of sequences were subsequently scaled using a centralized-logratio (Aitchison, 1982), which has shown to be effective in normalizing compositional data (Gloor et al, 2017).

Model inference is performed using variational Bayesian inference with mean-field assumption (Argelaguet et al, 2018). The resulting optimisation problem consists of an objective function that maximises the data likelihoods (i.e. the variance explained) under some sparsity assumptions (Argelaguet et al, 2019b) which yields a more interpretable model output.

After model fitting, the number of factors was estimated by requiring a minimum of $5 \%$ variance explained across all microbiome modalities. The downstream characterization of the model output included several analyses:

- Variance decomposition: quantification of the fraction of variance explained $\left(R_{2}\right)$ by each factor in each view, using a coefficient of determination (Argelaguet et al, 2019b, 2018, 2019a). 
- Visualization of weights: the model learns a weight for every feature in each factor, which can be interpreted as a measure of feature importance. Larger weights (in absolute value) indicate higher correlation with the corresponding factor values. The sign of the weight indicates the directionality of the variation: features with positive weights are positively associated with the corresponding values, whereas features with negative weights are negatively associated with the corresponding values.

- Visualization of factors: each MOFA factor captures a different dimension of heterogeneity in the microbiome composition. Mathematically, each factor ordinates cells along a one-dimensional axis centred at zero. Samples with different signs manifest opposite phenotypes along the inferred axis of variation, with higher absolute value indicating a stronger effect. Note that the interpretation of factors is analogous to the interpretation of the principal components in PCA.

- Data reconstruction: MOFA generates a compressed low-dimensional representation of the data. By taking the product of the factors and the weights, the model can reconstruct a normally-distributed denoised representation of the input data. This is particularly useful for the visualisation of sparse readouts.

\section{Statistics}

All analyses were performed in the $R$ statistical framework (Vienna Austria, version 3.6.1). To assess alpha diversity and richness, we calculated the Shannon Diversity Index and Observed Taxa Richness index with the phyloseq package 17. Data were not normally distributed and are therefore presented as median and interquartile range (IQR), while data were analysed using a Wilcoxon rank-sum test. Associations between Factor values and covariates were analysed using linear regression by Pearson correlation coefficients. Statistical significance is called at $10 \%$ FDR.

\section{Data availability}

Raw sequencing data (bacterial and fungal ASVs, VIDISCA-NGS sequencing reads) will be submitted to the European Nucleotide Archive (ENA; accession number PRJEB37289) prior to publication. All code used for analysis is available at https://github.com/bwhaak/MOFA_microbiome. Links to the processed data are included in the GitHub repository. 


\section{Acknowledgements}

429 The authors acknowledge Lonneke A. van Vught, Maryse A. Wiewel, Friso M. de Beer, Lieuwe 430 D.J. Bos, Gerie J. Glas, Roosmarijn T.M. van Hooijdonk, Michaëla A.M. Huson, Laura R.A. 431 Schouten, Marleen Straat, Esther Witteveen, and Luuk Wieske (Department of Intensive Care, 432 Amsterdam UMC, Location Academic Medical Center, the Netherlands) for their participation 433 in data collection. The authors would also like to thank Jorn Hartman, Michelle Klein, Martin 434 Deijs, Maarten Jebbink, Patricia Broekhuizen - van Haaften and Ellen Wentink - Bonnema for 435 their indispensable help in the laboratory work on the faecal samples. This work was supported 436 by the Netherlands Organization for Scientific Research (NWO; Vidi Grant 91716475).

\section{Author contributions}

438 BWH and WJW conceived the original study. RA performed the MOFA+ analysis. CMK and $439 \mathrm{CMvdH}$ designed and performed the viral sequencing and bioinformatics pipeline. SK and MG 440 designed and performed the NMR analyses. Fungal profiling and sequencing was designed 441 and performed by WdJ and TBMH. Protozoal analysis was overseen by TG. Microbiome 442 sequencing and initial analysis was performed and facilitated by RFK, FH and WMdV. MS and 443 TvdP oversaw sample collection on the ICU, JML oversaw sample collection of the healthy 444 subjects. BWH, RFK and RA analysed the data, wrote the original manuscript, and prepared 445 the final figures. CMvdH and WJW secured funding for this project. All authors have seen and approved the final version of the manuscript.

\section{Conflict of interest}

The authors declare no conflicts of interest 


\section{References}

Agudelo-Ochoa GM, Valdés-Duque BE, Giraldo-Giraldo NA, Jaillier-Ramírez AM, GiraldoVilla A, Acevedo-Castaño I, Yepes-Molina MA, Barbosa-Barbosa J \& Benítez-Paéz A (2020) Gut microbiota profiles in critically ill patients, potential biomarkers and risk variables for sepsis. Gut Microbes: 1-16 Available at: https://www.tandfonline.com/doi/full/10.1080/19490976.2019.1707610

Aitchison J (1982) The Statistical Analysis of Compositional Data. J. R. Stat. Soc. Ser. B 44: 139-160 Available at: http://doi.wiley.com/10.1111/j.2517-6161.1982.tb01195.x

Alverdy JC \& Krezalek MA (2017) Collapse of the Microbiome, Emergence of the Pathobiome, and the Immunopathology of Sepsis. Crit. Care Med. 45: 337-347 Available at: http://journals.Iww.com/00003246-201702000-00023

Argelaguet R, Arnol D, Bredikhin D, Deloro Y, Velten B, Marioni JC \& Stegle O (2019a) MOFA+: a probabilistic framework for comprehensive integration of structured singlecell data. bioRxiv: 837104 Available at:

https://www.biorxiv.org/content/10.1101/837104v1

Argelaguet R, Clark SJ, Mohammed H, Stapel LC, Krueger C, Kapourani C-A, ImazRosshandler I, Lohoff T, Xiang Y, Hanna CW, Smallwood S, Ibarra-Soria X, Buettner F, Sanguinetti G, Xie W, Krueger F, Göttgens B, Rugg-Gunn PJ, Kelsey G, Dean W, et al (2019b) Multi-omics profiling of mouse gastrulation at single-cell resolution. Nature Available at: http://www.ncbi.nlm.nih.gov/pubmed/31827285

Argelaguet R, Velten B, Arnol D, Dietrich S, Zenz T, Marioni JC, Buettner F, Huber W \& Stegle O (2018) Multi-Omics Factor Analysis-a framework for unsupervised integration of multi-omics data sets. Mol. Syst. Biol. 14: 1-13 Available at:

https://www.ncbi.nlm.nih.gov/pubmed/29925568

Arzmi MH, Dashper S, Catmull D, Cirillo N, Reynolds EC \& McCullough M (2015) Coaggregation of Candida albicans, Actinomyces naeslundii and Streptococcus mutans is Candida albicans strain dependent. FEMS Yeast Res. 15:

Belkaid Y \& Hand TW (2014) Role of the microbiota in immunity and inflammation. Cell 157: 121-141 Available at: http://dx.doi.org/10.1016/j.cell.2014.03.011

Beyda ND, Chuang SH, Alam MJ, Shah DN, Ng TM, McCaskey L \& Garey KW (2013) Treatment of Candida famata bloodstream infections: case series and review of the 
literature. J. Antimicrob. Chemother. 68: 438-443 Available at: https://academic.oup.com/jac/article-lookup/doi/10.1093/jac/dks388

Boom R, Sol CJ, Salimans MM, Jansen CL, Wertheim-van Dillen PM \& van der Noordaa J (1990) Rapid and simple method for purification of nucleic acids. J. Clin. Microbiol. 28: 495-503 Available at: http://www.ncbi.nlm.nih.gov/pubmed/1691208

Botschuijver S, Roeselers G, Levin E, Jonkers DM, Welting O, Heinsbroek SEM, de Weerd $\mathrm{HH}$, Boekhout T, Fornai M, Masclee AA, Schuren FHJ, de Jonge WJ, Seppen J \& van den Wijngaard RM (2017) Intestinal Fungal Dysbiosis Is Associated With Visceral Hypersensitivity in Patients With Irritable Bowel Syndrome and Rats. Gastroenterology 153: $1026-1039$

Buffie CG \& Pamer EG (2013) Microbiota-mediated colonization resistance against intestinal pathogens. Nat Rev Immunol 13: 790-801 Available at: http://www.ncbi.nlm.nih.gov/pubmed/24096337

Byrd AL, Perez-Rogers JF, Manimaran S, Castro-Nallar E, Toma I, McCaffrey T, Siegel M, Benson G, Crandall KA \& Johnson WE (2014) Clinical PathoScope: Rapid alignment and filtration for accurate pathogen identification in clinical samples using unassembled sequencing data. BMC Bioinformatics 15: 1-14

Callahan BJ, McMurdie PJ, Rosen MJ, Han AW, Johnson AJA \& Holmes SP (2016) DADA2: High-resolution sample inference from Illumina amplicon data. Nat. Methods 13: 581583 Available at: http://www.nature.com/articles/nmeth.3869

Clarke TB, Davis KM, Lysenko ES, Zhou AY, Yu Y \& Weiser JN (2010) Recognition of peptidoglycan from the microbiota by Nod1 enhances systemic innate immunity. Nat. Med. 16: 228-31 Available at: http://dx.doi.org/10.1038/nm.2087

Costea PI, Zeller G, Sunagawa S, Pelletier E, Alberti A, Levenez F, Tramontano M, Driessen M, Hercog R, Jung F-E, Kultima JR, Hayward MR, Coelho LP, Allen-Vercoe E, Bertrand L, Blaut M, Brown JRM, Carton T, Cools-Portier S, Daigneault M, et al (2017) Towards standards for human fecal sample processing in metagenomic studies. Nat. Biotechnol. 35: 1069-1076 Available at: http://www.nature.com/articles/nbt.3960

Dutilh BE, Cassman N, McNair K, Sanchez SE, Silva GGZ, Boling L, Barr JJ, Speth DR, Seguritan V, Aziz RK, Felts B, Dinsdale EA, Mokili JL \& Edwards RA (2014) A highly abundant bacteriophage discovered in the unknown sequences of human faecal metagenomes. Nat. Commun. 5: 1-11 Available at: 
https://www.ncbi.nlm.nih.gov/pubmed/25058116

513

514

515

516

517

518

519

520

521

522

523

524

525

526

527

528

529

530

531

532

533

534

535

536

537

538

539

540

541

Edgar RC (2010) Search and clustering orders of magnitude faster than BLAST.

Bioinformatics 26: 2460-2461 Available at:

https://academic.oup.com/bioinformatics/article-

lookup/doi/10.1093/bioinformatics/btq461

Edridge AWD, Deijs M, Van Zeggeren IE, Kinsella CM, Jebbink MF, Bakker M, Van de Beek D, Brouwer MC \& Van der Hoek L (2019) Viral metagenomics on cerebrospinal fluid. Genes (Basel). 10:

Endoh D, Mizutani T, Kirisawa R, Maki Y, Saito H, Kon Y, Morikawa S \& Hayashi M (2005) Species-independent detection of RNA virus by representational difference analysis using non-ribosomal hexanucleotides for reverse transcription. Nucleic Acids Res. 33: e65 Available at: https://academic.oup.com/nar/article-lookup/doi/10.1093/nar/gni064

Fan D, Coughlin LA, Neubauer MM, Kim J, Kim MS, Zhan X, Simms-Waldrip TR, Xie Y, Hooper L V \& Koh AY (2015) Activation of HIF-1 $\alpha$ and LL-37 by commensal bacteria inhibits Candida albicans colonization. Nat. Med. 21: 808-814 Available at: http://www.nature.com/articles/nm.3871

García C, Tebbji F, Daigneault M, Liu N-N, Köhler JR, Allen-Vercoe E \& Sellam A (2017) The Human Gut Microbial Metabolome Modulates Fungal Growth via the TOR Signaling Pathway. mSphere 2: 1-15

Ghabrial SA, Castón JR, Jiang D, Nibert ML \& Suzuki N (2015) 50-plus years of fungal viruses. Virology 479-480: 356-368

Gloor GB, Macklaim JM, Pawlowsky-Glahn V \& Egozcue JJ (2017) Microbiome datasets are compositional: And this is not optional. Front. Microbiol. 8: 1-6

Haak BW, Lankelma JM, Hugenholtz F, Belzer C, De Vos WM \& Wiersinga WJ (2019) Longterm impact of oral vancomycin, ciprofloxacin and metronidazole on the gut microbiota in healthy humans. J. Antimicrob. Chemother. 74: 782-786 Available at: https://www.ncbi.nlm.nih.gov/pubmed/30418539

Haak BW, Levi M \& Wiersinga WJ (2017) Microbiota-targeted therapies on the intensive care unit. Curr. Opin. Crit. Care 23: 167-174 Available at: https://www.ncbi.nlm.nih.gov/pubmed/28092309 
Haak BW \& Wiersinga WJ (2017) The role of the gut microbiota in sepsis. Lancet Gastroenterol. Hepatol. 2: 135-143

Hallen-adams HE \& Suhr MJ (2017) Fungi in the healthy human gastrointestinal tract. Virulence 8: 352-358 Available at: http://dx.doi.org/10.1080/21505594.2016.1247140

van Hattem JM, Arcilla MS, Grobusch MP, Bart A, Bootsma MC, van Genderen PJ, van Gool T, Goorhuis A, van Hellemond JJ, Molenkamp R, Molhoek N, Oude Lashof AM, Stobberingh EE, de Wever B, Verbrugh HA, Melles DC, Penders J, Schultsz C \& de Jong MD (2017) Travel-related acquisition of diarrhoeagenic bacteria, enteral viruses and parasites in a prospective cohort of 98 Dutch travellers. Travel Med. Infect. Dis. 19: 33-36 Available at: https://doi.org/10.1016/j.tmaid.2017.08.003

van Hattem JM, Arcilla MS, Schultsz C, Bootsma MC, Verhaar N, Rebers SP, Goorhuis A, Grobusch MP, Penders J, de Jong MD, van Gool T, Bart A, van Genderen PJ, Melles DC, Molhoek N, Oude Lashof AM, Stobberingh EE \& Verbrugh HA (2019) Carriage of Blastocystis spp. in travellers - A prospective longitudinal study. Travel Med. Infect. Dis. 27: 87-91 Available at: https://doi.org/10.1016/j.tmaid.2018.06.005

van der Hoek L, de Vries M, Oude Munnink BB, Deijs M, Canuti M, Koekkoek SM, Molenkamp R, Bakker M, Jurriaans S, van Schaik BDC, Luyf AC, Olabarriaga SD \& van Kampen AHC (2012) Performance of VIDISCA-454 in feces-suspensions and serum. Viruses 4: 1328-1334

Honda K \& Littman DR (2012) The microbiome in infectious disease and inflammation. Annu. Rev. Immunol. 30: 759-95 Available at: http://apps.webofknowledge.com.proxy.library.nd.edu/full_record.do?product=WOS\&se arch_mode $=$ GeneralSearch\&qid $=2 \& S I D=4 B d S D x g 2 Y M J D c E D k 2 L 6 \&$ page $=2 \& d o c=20$

Hong C, Manimaran S, Shen Y, Perez-Rogers JF, Byrd AL, Castro-Nallar E, Crandall KA \& Johnson WE (2014) PathoScope 2.0: A complete computational framework for strain identification in environmental or clinical sequencing samples. Microbiome 2:

Huseyin CE, O'Toole PW, Cotter PD \& Scanlan PD (2017) Forgotten fungi-the gut mycobiome in human health and disease. FEMS Microbiol. Rev. 41: 479-511

Kim D, Sengupta A, Niepa THR, Lee BH, Weljie A, Freitas-Blanco VS, Murata RM, Stebe KJ, Lee D \& Koo H (2017) Candida albicans stimulates Streptococcus mutans microcolony development via cross-kingdom biofilm-derived metabolites. Sci. Rep. 7: 
Kim HK, Kostidis S \& Choi YH (2018) NMR analysis of fecal samples. In Methods in Molecular Biology, Giera M (ed) Springer Science + Business Media, LLC

Kinsella CM, Deijs M \& van der Hoek L (2019) Enhanced bioinformatic profiling of VIDISCA libraries for virus detection and discovery. Virus Res. 263: 21-26 Available at: https://doi.org/10.1016/j.virusres.2018.12.010

Knowles B, Silveira CB, Bailey BA, Barott K, Cantu VA, Cobian-Guëmes AG, Coutinho FH, Dinsdale EA, Felts B, Furby KA, George EE, Green KT, Gregoracci GB, Haas AF, Haggerty JM, Hester ER, Hisakawa N, Kelly LW, Lim YW, Little M, et al (2016) Lytic to temperate switching of viral communities. Nature 531: 466-470 Available at: https://www.ncbi.nlm.nih.gov/pubmed/26982729

Kong EF, Tsui C, Kucharíková S, Van Dijck P \& Jabra-Rizk MA (2017) Modulation of Staphylococcus aureus Response to Antimicrobials by the Candida albicans Quorum Sensing Molecule Farnesol. Antimicrob. Agents Chemother. 61: Available at: http://aac.asm.org/lookup/doi/10.1128/AAC.01573-17

Kozich JJ, Westcott SL, Baxter NT, Highlander SK \& Schloss PD (2013) Development of a Dual-Index Sequencing Strategy and Curation Pipeline for Analyzing Amplicon Sequence Data on the MiSeq Illumina Sequencing Platform. Appl. Environ. Microbiol. 79: 5112-5120 Available at: http://aem.asm.org/lookup/doi/10.1128/AEM.01043-13

Kuss SK, Best GT, Etheredge CA, Pruijssers AJ, Frierson JM, Hooper L V., Dermody TS \& Pfeiffer JK (2011) Intestinal Microbiota Promote Enteric Virus Replication and Systemic Pathogenesis. Science (80-. ). 334: 249-252 Available at: http://www.sciencemag.org/cgi/doi/10.1126/science.1211057

Lankelma JM, Cranendonk DR, Belzer C, De Vos AF, De Vos WM, Van Der Poll T \& Wiersinga WJ (2017a) Antibiotic-induced gut microbiota disruption during human endotoxemia: A randomised controlled study. Gut 66: 1623-1630

Lankelma JM, van Vught LA, Belzer C, Schultz MJ, van der Poll T, de Vos WM, Wiersinga WJ, Vught LA Van, Belzer C, Schultz MJ, Poll T Van Der, Vos WM De \& Wiersinga WJ (2017b) Critically ill patients demonstrate large interpersonal variation in intestinal microbiota dysregulation : a pilot study. Intensive Care Med. 43: 59-68

Lee YJ, Arguello ES, Jenq RR, Littmann E, Kim GJ, Miller LC, Ling L, Figueroa C, Robilotti E, Perales M-A, Barker JN, Giralt S, van den Brink MRM, Pamer EG \& Taur Y (2017) Protective Factors in the Intestinal Microbiome Against Clostridium difficile Infection in 
Recipients of Allogeneic Hematopoietic Stem Cell Transplantation. J. Infect. Dis. 215: 1117-1123 Available at: https://academic.oup.com/jid/article/215/7/1117/3813430

Legoff J, Resche-Rigon M, Bouquet J, Robin M, Naccache SN, Mercier-Delarue S, Federman S, Samayoa E, Rousseau C, Piron P, Kapel N, Simon F, Socié G \& Chiu CY (2017) The eukaryotic gut virome in hematopoietic stem cell transplantation: New clues in enteric graft-versus-host disease. Nat. Med. 23: 1080-1085 Available at: http://dx.doi.org/10.1038/nm.4380

Li H (2013) Aligning sequence reads, clone sequences and assembly contigs with BWAMEM. arXiv Available at: http://arxiv.org/abs/1303.3997

Liu CM, Kachur S, Dwan MG, Abraham AG, Aziz M, Hsueh P-R, Huang Y-T, Busch JD, Lamit LJ, Gehring CA, Keim P \& Price LB (2012) FungiQuant: A broad-coverage fungal quantitative real-time PCR assay. BMC Microbiol. 12: 255 Available at: http://bmcmicrobiol.biomedcentral.com/articles/10.1186/1471-2180-12-255

McDonald D, Ackermann G, Khailova L, Baird C, Heyland D, Kozar R, Lemieux M, Derenski K, King J, Vis-Kampen C, Knight R \& Wischmeyer PE (2016) Extreme Dysbiosis of the Microbiome in Critical IIIness. $m$ Sphere 1: 1-6 Available at: http://msphere.asm.org/lookup/doi/10.1128/mSphere.00199-16

Miceli MH, Díaz JA \& Lee SA (2011) Emerging opportunistic yeast infections. Lancet Infect. Dis. 11: 142-151 Available at: http://dx.doi.org/10.1016/S1473-3099(10)70218-8

Nadkarni MA, Martin FE, Jacques NA \& Hunter N (2002) Determination of bacterial load by real-time PCR using a broad-range (universal) probe and primers set. Microbiology 148: 257-266 Available at: https://www.microbiologyresearch.org/content/journal/micro/10.1099/00221287-148-1257

Nash AK, Auchtung TA, Wong MC, Smith DP, Gesell JR, Ross MC, Stewart CJ, Metcalf GA, Muzny DM, Gibbs RA, Ajami NJ \& Petrosino JF (2017) The gut mycobiome of the Human Microbiome Project healthy cohort. Microbiome 5: 153 Available at: https://www.ncbi.nlm.nih.gov/pubmed/29178920

Neil JA \& Cadwell K (2018) The Intestinal Virome and Immunity. J. Immunol. 201: 16151624 Available at: https://www.ncbi.nlm.nih.gov/pubmed/30181300

Nguyen LN, Lopes LCL, Cordero RJBB \& Nosanchuk JD (2011) Sodium butyrate inhibits 

pathogenic yeast growth and enhances the functions of macrophages. J. Antimicrob. Chemother. 66: 2573-2580 Available at: https://www.ncbi.nlm.nih.gov/pubmed/21911344

Nilsson RH, Larsson K-H, Taylor AFS, Bengtsson-Palme J, Jeppesen TS, Schigel D, Kennedy P, Picard K, Glöckner FO, Tedersoo L, Saar I, Kõljalg U \& Abarenkov K (2019) The UNITE database for molecular identification of fungi: handling dark taxa and parallel taxonomic classifications. Nucleic Acids Res. 47: D259-D264 Available at: https://academic.oup.com/nar/article/47/D1/D259/5146189

Norman JM, Handley SA \& Virgin HW (2014) Kingdom-Agnostic Metagenomics and the Importance of Complete Characterization of Enteric Microbial Communities. Gastroenterology 146: 1459-1469 Available at: https://www.ncbi.nlm.nih.gov/pmc/articles/PMC3624763/pdf/nihms412728.pdf

Pfeiffer JK \& Virgin HW (2016) Transkingdom control of viral infection and immunity in the mammalian intestine. Science (80-. ). 351: aad5872-aad5872 Available at: https://linkinghub.elsevier.com/retrieve/pii/S0031938416312148

Quast C, Pruesse E, Yilmaz P, Gerken J, Schweer T, Yarza P, Peplies J \& Glöckner FO (2013) The SILVA ribosomal RNA gene database project: Improved data processing and web-based tools. Nucleic Acids Res. 41: 590-596

Richard ML \& Sokol H (2019) The gut mycobiota: insights into analysis, environmental interactions and role in gastrointestinal diseases. Nat. Rev. Gastroenterol. Hepatol. 16: 331-345 Available at: http://dx.doi.org/10.1038/s41575-019-0121-2

Ruijter JM, Ramakers C, Hoogaars WMH, Karlen Y, Bakker O, van den Hoff MJB \& Moorman AFM (2009) Amplification efficiency: linking baseline and bias in the analysis of quantitative PCR data. Nucleic Acids Res. 37: e45-e45 Available at: https://academic.oup.com/nar/article-lookup/doi/10.1093/nar/gkp045

Schuijt TJ (2015) The gut microbiota plays a protective role in the host defence against pneumococcal pneumonia. Gut: 1-9 Available at: http://gut.bmj.com/content/early/2015/10/28/gutjnl-2015-309728?papetoc

Shkoporov AN, Clooney AG, Sutton TDS, Ryan FJ, Daly KM, Nolan JA, McDonnell SA, Khokhlova E V., Draper LA, Forde A, Guerin E, Velayudhan V, Ross RP \& Hill C (2019) The Human Gut Virome Is Highly Diverse, Stable, and Individual Specific. Cell Host Microbe 26: 527-541.e5 Available at: https://doi.org/10.1016/j.chom.2019.09.009 
Shkoporov AN \& Hill C (2019) Bacteriophages of the Human Gut: The "Known Unknown" of the Microbiome. Cell Host Microbe 25: 195-209 Available at: https://doi.org/10.1016/j.chom.2019.01.017

Shkoporov AN, Khokhlova E V., Fitzgerald CB, Stockdale SR, Draper LA, Ross RP \& Hill C (2018) ФCrAss001 represents the most abundant bacteriophage family in the human gut and infects Bacteroides intestinalis. Nat. Commun. 9: 1-8 Available at: http://dx.doi.org/10.1038/s41467-018-07225-7

Sokol H, Leducq V, Aschard H, Pham HP, Jegou S, Landman C, Cohen D, Liguori G, Bourrier A, Nion-Larmurier I, Cosnes J, Seksik P, Langella P, Skurnik D, Richard ML \& Beaugerie L (2017) Fungal microbiota dysbiosis in IBD. Gut 66: 1039-1048 Available at: https://www.ncbi.nlm.nih.gov/pubmed/26843508

De Sordi L, Lourenço M \& Debarbieux L (2019) The Battle Within: Interactions of Bacteriophages and Bacteria in the Gastrointestinal Tract. Cell Host Microbe 25: 210218 Available at: https://linkinghub.elsevier.com/retrieve/pii/S1931312819300587

Sovran B, Planchais J, Jegou S, Straube M, Lamas B, Natividad JM, Agus A, Dupraz L, Glodt J, Da Costa G, Michel M-L, Langella P, Richard ML \& Sokol H (2018) Enterobacteriaceae are essential for the modulation of colitis severity by fungi. Microbiome 6: 152 Available at: https://microbiomejournal.biomedcentral.com/articles/10.1186/s40168-018-0538-9

Suhr MJ \& Hallen-Adams HE (2015) The human gut mycobiome: Pitfalls and potentials-a mycologist's perspective. Mycologia 107: 1057-1073

Taur Y, Xavier JB, Lipuma L, Ubeda C, Goldberg J, Gobourne A, Lee YJ, Dubin KA, Socci ND, Viale A, Perales M-A, Jenq RR, van den Brink MRM \& Pamer EG (2012) Intestinal Domination and the Risk of Bacteremia in Patients Undergoing Allogeneic Hematopoietic Stem Cell Transplantation. Clin. Infect. Dis. 55: 905-914 Available at: https://academic.oup.com/cid/article-lookup/doi/10.1093/cid/cis580

Uppuluri P, Busscher HJ, Chakladar J, van der Mei HC \& LaJean Chaffin W (2017) Transcriptional profiling of C. albicans in a two species biofilm with Rothia dentocariosa. Front. Cell. Infect. Microbiol. 7:

van Vught LA, Klein Klouwenberg PMC, Spitoni C, Scicluna BP, Wiewel MA, Horn J, Schultz MJ, Nürnberg P, Bonten MJM, Cremer OL \& van der Poll T (2016) Incidence, Risk Factors, and Attributable Mortality of Secondary Infections in the Intensive Care Unit 
After Admission for Sepsis. JAMA 315: 1469 Available at: http://jama.jamanetwork.com/article.aspx?doi=10.1001/jama.2016.2691

Wang Q, Garrity GM, Tiedje JM \& Cole JR (2007) Naive Bayesian Classifier for Rapid Assignment of rRNA Sequences into the New Bacterial Taxonomy. Appl. Environ. Microbiol. 73: 5261-5267 Available at: http://aem.asm.org/cgi/doi/10.1128/AEM.0006207

Wischmeyer PE, McDonald D \& Knight R (2016) Role of the microbiome, probiotics, and 'dysbiosis therapy' in critical illness. Curr. Opin. Crit. Care 22: 347-353 Available at: https://www.ncbi.nlm.nih.gov/pubmed/27327243

Zaborin D. and Garfield, K. and Quensen, J. and Shakhsheer, B. and Kade, M. and Tirrell, M. and Tiedje, J. and Gilbert, J. A. and Zaborina, O. and Alverdy, J. C. A and S Membership and behavior of ultra-low-diversity pathogen communities present in the gut of humans during prolonged critical illness. MBio 5: e01361-14

Zhai B, Ola M, Rolling T, Tosini NL, Joshowitz S, Littmann ER, Amoretti LA, Fontana E, Wright RJ, Miranda E, Veelken CA, Morjaria SM, Peled JU, van den Brink MRM, Babady NE, Butler G, Taur Y \& Hohl TM (2020) High-resolution mycobiota analysis reveals dynamic intestinal translocation preceding invasive candidiasis. Nat. Med. 26: 59-64 Available at: http://dx.doi.org/10.1038/s41591-019-0709-7

Zuo T, Lu XJ, Zhang Y, Cheung CP, Lam S, Zhang F, Tang W, Ching JYL, Zhao R, Chan PKS, Sung JJY, Yu J, Chan FKL, Cao Q, Sheng JQ \& Ng SC (2019) Gut mucosal virome alterations in ulcerative colitis. Gut 68: 1169-1179 